\title{
Integrated processing of ferriferous materials in blank production for mechanical engineering facilities
}

\author{
Valery Predein ${ }^{1}$, Artyom Popov ${ }^{1}$, Oleg Komarov ${ }^{1}$ and Sergey Zhilin ${ }^{1, *}$ \\ ${ }^{1}$ Institute of Machinery and Metallurgy, Far-Eastern Branch of the Russian Academy \\ of Sciences, Komsomolsk-on-Amur, 681005 Russian Federation
}

\begin{abstract}
The paper considers the possibility of reducing the use of crude ore for metal product by using aluminothermy, which facilitates effective integrated processing of metal waste generated by engineering and metallurgy facilities in the form of mill scale, ferrous and non-ferrous metal swarf with simultaneous castings production. The paper studies the impact patterns of thermite components ratios on the parameters of extracting chemical elements from the source components, metal phase output and its chemical composition. The possible applications for experimental alloys resulting from controlled exothermic reactions are determined for supplying castings and melting stock to blank production for mechanical engineering facilities.
\end{abstract}

\section{Introduction}

Mining and metallurgy are collinear technological paths in multi-operation production cycles from ore mining to ready materials and products. Expensive crude ore, complex and multi-stage processing, known mineral deposit depletion, low level of geological exploration mean that production cycle requires recycled materials including metal waste of mechanical engineering and metallurgy facilities which have a high potential to reduce the mining load as a whole. Waste dumps of large metallurgy facilities contain hundreds of thousands of scale [1]. Using such manufactured mineral formations, including metal waste, has a number of advantages: availability, low cost, high concentration of certain elements that reduces time and cost of final product production [2, 3]. Currently, waste-processing using known technological methods is at best technologically and economically ineffective [4]. Developing new and improving known production waste processing methods is a relevant scientific and technical issue. Its solution will not only reduce a number of certain social and economic regional issues but improve their environmental situation as a whole. Effective metal waste processing is

\footnotetext{
* Corresponding author: sergeyzhilin1@rambler.ru
} 
most relevant for mechanical engineering and metallurgy which generate a large amount of ferrous and non-ferrous metal swarf, scale, slag. Metal swarf is processed by traditional remelting with a high rate of melting and nonrecoverable loss which reduces mass suitable alloy output. Metallurgical scale and slag have a high concentration of useful elements in varying combinations, but they are almost never used or processed and get dumped. Ferrous and non-ferrous metal scale and slag processing while simultaneously obtaining ready products with required properties in the form of castings and melting stock from iron-carbon and intermetallic alloys, in particular Fe-Al systems, is to be performed by aluminothermy using thermites based on the specified metal waste. Regulating thermites and varying initial reaction conditions facilitate the production of a large range of alloys, including those used to obtain critical mining castings.

Aluminothermy differs from other technological methods by a number of certain advantages [5]. Process autogenicity due to the exothermic reaction occurring in the mixtures is the most important part as it allows reducing or excluding the use of external energy sources. This, in turn, allows using aluminothermy out of specialized departments, including at metal waste dumps. Application of the developed technological processes does not require expensive source materials, allows using additives of varying fraction, composition and properties when forming mixtures. The reductant in thermites is mostly aluminum alloy swarf, which reduces scale (iron oxide compounds) [6]. In addition, the mixture may contain various fillers ensuring reaction temperature and the properties of the made alloys. Exothermic reaction in thermites results in liquid metal phases and slag. From the technological point of view, metal phase containing a number of chemical elements is the most interesting. Depending on the initial reductant content in the thermites, metal may refer to iron-carbon or intermetallic Fe-Al alloys which are highly interesting to researchers and scientists of the world due to their unique properties [7, 8, and 9]. Slag is based on aluminum oxides and impurity elements, which is highly promising for manufacturing chemically stable and highly refractory materials and products as well as raw material for producing alumina together with bauxite and nephelinic ores or instead of them. Aluminothermy allows determining the possibility of obtaining not only melting stock for further traditional remelting, but also semi-finished materials and castings with predictable properties. High temperatures exceeding $3000{ }^{\circ} \mathrm{C}$ in a number of cases occur during reduction and facilitate making iron-carbon alloys using high-melting-point materials. For example, alloying with tungsten, which is easy to dissolve in iron base, allows obtaining compounds with high mechanical characteristics [10].

Preliminary studies established that there is a change in the coefficient of element extraction from the reacting initial components and their shift to metal phase as well as metal phase quantity, depending on the ratio of reductant and iron oxide in the thermite base composition. Using aluminum oxides with varying impurity element content as reductants also influences very metal phase output and element extraction. It has been established that the lower active aluminum content in the alloy is, the lower specified process parameters are [11]. When thermites contain $20-25 \%$ of reductant during exothermic reactions, the changes in element extraction from initial components and their shift to experimental alloys are the most significant. This range was studied with $1 \%$ iteration. It has been established that 
minimal reductant content leads to lower possibility of impurity element extraction which alloys making alloys with total impurity element content no more than $0.55 \%$. Metal phase output is significantly lower. To correct chemical composition and physicomechanical properties of the made alloys, various fillers may be added, for example, scheelite concentrate. Tungsten is extracted from the concentrate during the reaction. Tungsten is then added to the liquid melt, increasing its hardness and strength. It is impossible to use scheelite concentrate in traditional melting and for obtaining liquid melt for tungsten alloying, as this requires pure compounds.

\section{Purpose and Goals}

The purpose hereof is to study the possibility of effective metal scale and applied filler processing using aluminothermy, which is determined by experimental alloy output and coefficient of element extraction depending on reductant, and filler content in thermites.

The following goals were achieved during purpose implementation:

- $\quad$ obtaining samples by aluminothermy using thermites composed of metallurgy scale, reductants and scheelite concentrate;

- $\quad$ establishing impact patterns of various thermite reductants ratios on the reaction output and extracting elements from source materials;

- determining the impact of scheelite concentrate content on the reaction output and element extraction;

- $\quad$ obtaining sample castings by aluminothermy and determining the possibility of further processing of low quality castings obtained experimentally using traditional melting units.

\section{Description of Experiment and Study Methods}

Exothermic reactions are performed in refractory crucibles made of graphite electrode scrap, which were used for melting steel in electric arc furnaces. Electrodes ЭГ15 conforming to Spec 14-139-177-2003 "Graphite Electrodes dia.75-555 mm and Nipples for Them. Specifications". Refractory material density is $1700 \mathrm{~kg} / \mathrm{m}^{3}$. The volume of crucible working space is $0.000572 \mathrm{~m}^{3}$, wall thickness is $0.01 \mathrm{~m}$, mass is $0.71 \mathrm{~kg}$. Working space volume corresponds to the mixture filling of $1 \mathrm{~kg}$ with minimal pour density (no compacting) to obtain a sample of a required size. After the mixture is poured, the crucible is covered by a lid with a vent hole (dia. $0.02 \mathrm{~m}$ ). Inner crucible diameter equals the height of its working space and is $0.09 \mathrm{~m}$. A replaceable insert is put into the crucible bottom with a hole dia. $0.007 \mathrm{~m}$ to stabilize liquid metal pouring speed. A spout hole is closed with a cone plug made of same grade graphite. After the reaction is finished, and liquid metal stays in the crucible for 10 seconds (to ensure separation of metal and slag), the plug is removed and metal is poured into a mold. A sampling mold is a closed-bottom cylinder with inner dia. $0.03 \mathrm{~m}$, wall thickness $0.03 \mathrm{~m}$ and height $0.15 \mathrm{~m}$. prior to the experiments, refractory fittings are heated up to $150{ }^{\circ} \mathrm{C}$ and covered with anti-stick paint of the following composition: powder quartz $20 \%$, liquid glass $5 \%$, water $74 \%$, boracic acid $1 \%$.

Thermites contain components of fractions $0.2 \div 1.5 \mathrm{~mm}$ with the following chemical composition: aluminum alloy swarf (reductant 1$) \mathrm{Al}=$ 
$98.627 \% ; \mathrm{Cu}=0.018 \% ; \mathrm{Si}=0.855 \% ; \mathrm{Mn}=0.019 \% ; \mathrm{Fe}=0.462 \% ; \mathrm{Cr}=$ $0.016 \%$; $\mathrm{Ni}=0.004 \%$; aluminum alloy swarf (reductant 2 ) $\mathrm{Al}=89.443 \%$; $\mathrm{Mn}=0.304 \% ; \mathrm{Si}=1.097 \% ; \mathrm{Cr}=0.062 \% ; \mathrm{Ni}=0.008 \% ; \mathrm{Cu}=2.040 \% ; \mathrm{Fe}$ $=0.166 \% ; \mathrm{Mg}=3.917 \% ; \mathrm{Zn}=2.961 \%$; iron scale $\mathrm{Fe}=71.500 \% ; \mathrm{O}_{2}=$ $22.639 \% ; \mathrm{Si}=2.960 \% ; \mathrm{Mn}=1.188 \% ; \mathrm{Al}=0.697 \% ; \mathrm{Cu}=0.444 \% ; \mathrm{Ni}=$ $0.188 \% ; \mathrm{Cr}=0.173 \% ; \mathrm{C}=0.150 \% ; \mathrm{S}=0.030 \% ; \mathrm{P}=0.030 \%$; scheelite concentrate powder $\mathrm{WO}_{3}=3-50 \%$. $\mathrm{P}=1.7-2.0 \%$. Mo $=0.021 \%$. S $=0.25-0.3 \%$. As $\leq 0.005 \%$. SiO $=2-4.6 \% . \mathrm{CaO}=29 \%$.

Mechanical mixing of scale and aluminum alloys in the following ratios (\% mass) formed thermites: 20/80, 21/79, 22/78, 23/77, 24/76, 25/75.

Thermite preparation includes a sequence of such operations as mixing for $10 \mathrm{~min}$; drying at $150{ }^{\circ} \mathrm{C}$ for 1 hour; second mixing for 10 min during which the mixture becomes homogeneous and components are partially crushed. This leads to reductant fraction cleaning from oxide film and ensuring intense interaction between reacting particles.

Chemical composition of the initial thermite components was studied using an energy-dispersive X-ray fluorescence spectrometer EDX-8000 manufactured by Shimadzu (Japan). Chemical composition of the experimental samples was determined using a CCD based optical emission spectrometer TASMAN Q4 170 manufactured by BRUKER (USA). Metal phase output was determined as a ratio of reacting materials mass sum to the resulting metal phase mass. Mass was measured using scales MW-II by CAS (Korea). Extraction measure for certain elements was determined as the ratio of its content in the initial components to its content in the metal phase.

\section{Discussion}

The ratio of scale and reductant in thermite is one of the important factors defining exothermic reaction parameters that include reaction speed, temperature, and number of phases. When using energy-efficient resourcesaving technologies, top priority is to obtain the maximum amount of metal from a unit of mixture when ensuring the required chemical composition. The main scale element is iron with total quantity up to $76 \%$ by mass. Scale and aluminum are used in production. They are rich in impurity elements influencing the ratio of initial components needed to ensure the required quantity of active aluminum in mixtures. According to the conducted studies, increasing the content of considered reductants in thermites within 20-25\% ensures the conditions improving element extraction and, correspondingly, metal phase output. Figure $1(\mathrm{a}, \mathrm{b}, \mathrm{c})$ shows functional connections of the changing element share extracted from the reacting materials, metal phase output (Figure 1, d) and reductant quantity.

It was empirically determined that increasing the content of reductant 1 in thermite within range $20-25 \%$ leads to increasing metal output mass within range $42.3-52.6 \%$. Minimal mass output of metallized product is observed when using reductant 1 to oxidant ratio 20/80, and maximal output is $52.6 \%$ which corresponds to the ratio $25 / 75$. The largest output increase $23 \%$ by mass is observed when reductant 1 concentration changes from $20 \%$ to $22 \%$. The following change from $22 \%$ to $25 \%$ leads to a small studied parameter increase by $1.9 \%$. Further increase of aluminum content in mixtures insignificantly affects thermite metal mass output, but it leads to a high content of residual aluminum in the experimental alloy. The identified 
connection between thermite metal output and the amount of reductant 1 is also true for reductant 2 with different values, which are due to the high content of impurity elements and lower content of active aluminum. Reductant 2 ensures thermal metal output lower than when mixtures containing aluminum alloy swarf 1 are used by $4.7-20 \%$ in the considered content range for thermites.
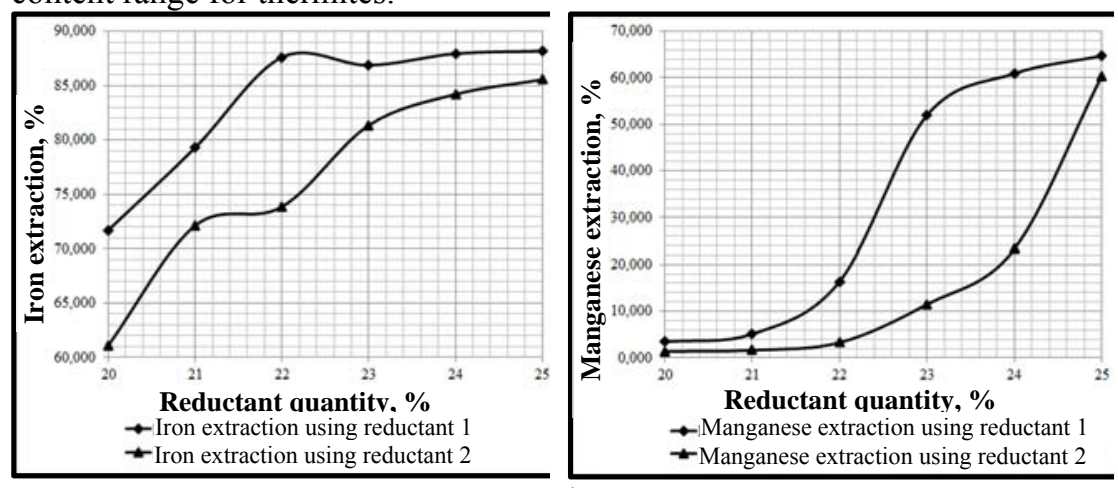

a.

b.
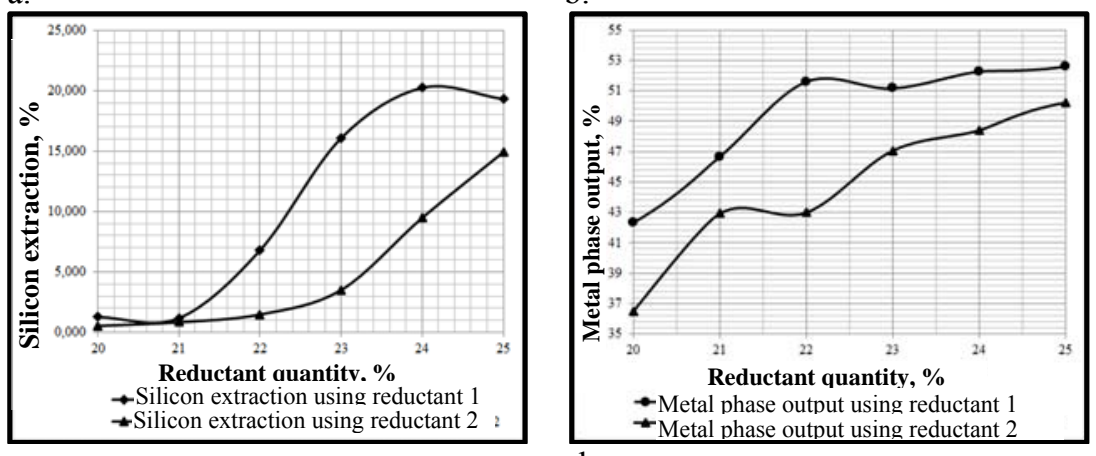

c.

d.

Fig. 1. Functional Connection of Chemical Element Extraction from Reacting Compounds during Aluminothermy (a, b, c), Metal Phase Output (d) and Thermite Components Ratio

Changing the ratio of reductant to scale leads to a change in the behavior of impurity chemical element capable of oxidation, reduction and melting loss. Depending on the elements state, stage sequence may be of any kind which affects their distribution between metal, slag and gas phases. Table 1 shows chemical compositions of the obtained experimental alloys.

It has been determined that manganese extraction from the initial thermite components within reductant 1 range $20-25 \%$ is $3.4-64.7 \%$. When using reductant 2 for melting stock in the specified range, manganese extraction is within 1.4-60.4\%. Fuller manganese extraction is observed when reductant content is high in the mixtures due to its effective reduction.

Based on this, manganese content in aluminothermic alloys is $0.06-$ $0.86 \%$ when introducing reductant 1 to thermites within range $20-25 \%$. A significant manganese increase in alloys is observed when reductant 1 content in mixtures shifts from 22 to $23 \%$ and its concentration changes from 0.23 to $0.76 \%$. The amount of reductant 1 in melting stock lower than $22 \%$ does not ensure fuller manganese extraction as it is all spent on iron extraction. The amount of reductant 1 above $23 \%$ does not lead to a significant manganese concentration increase. However, due to the increase 
in residual aluminum content, the created conditions decrease secondary oxidation of metal and its shift to slag. Such manganese behavior is observed when reductant 2 is used for melting stock. The main increase in manganese content in liquid metal is observed for the shift from 24 to $25 \%$ of reductant 2. Manganese concentration changes from 0.37 to $0.92 \%$ correspondingly. The increase of reductant 2 range ensuring maximum manganese extraction compared to reductant 1 mixtures is due to the low active aluminum concentration in reductant 2 that is $98.6 \%$ and $96.2 \%$ correspondingly.

The nature of silicon content change in the studied alloys is similar to that of manganese when using different reductant concentrations for thermite melting stock. As the results of the studies show, the use of reductant 1 leads to an almost linear silicon content increase within reductant range 21 to $24 \%$. The maximum increase is $0.35 \%$ in the range 22 to $23 \%$. Minimal amount is observed in the range $20-21 \%$ of reductant 1 for thermites with maximum silicon content $0.06 \%$. Reductant content above $24 \%$ in experimental alloys leads to silicon content decrease due to reduced silicon concentration in thermite melting stock. Silicon extraction from reacting thermite materials is maximum $1.3 \%$ when reductant 1 content is up to $21 \%$. Silicon extraction is $6.8-20.2 \%$ for reductant range $22-24 \%$. Reductant content $25 \%$ ensures $19.3 \%$ silicon extraction. When introducing reductant 2 , an insignificant silicon increase from 0.03 to $0.07 \%$ is ensured for reductant range $20-22 \%$; the extraction is $0.5-1.5 \%$. In the reductant, 2 range $23-25 \%$ in thermites, there is silicon extraction increase from 3.5 to $14.9 \%$. Maximum silicon extraction at high reductant concentrations in thermites is due to the high residual aluminum content in experimental alloys, which facilitates additional silicon extraction from source thermite materials. When using less than $21 \%$ of reductant for thermite melting stock, insignificant silicon extraction by metal phase is due to the fact that this ratio is unsatisfactory for full reduction of all oxides as iron oxides are reduced first.

Table 1. Chemical Composition of Experimental Alloys

\begin{tabular}{|c|c|c|c|c|c|c|c|}
\hline \multirow{2}{*}{ No. } & \multirow{2}{*}{ Element } & \multicolumn{7}{|c|}{ Reductant Content, \% } \\
\cline { 3 - 7 } & & 20 & 21 & 22 & 23 & 24 & 25 \\
\hline 1 & $\mathrm{C}$ & $0.250 /$ & $1.340 /$ & $1.990 /$ & $1.850 /$ & $1.580 /$ & $1.470 /$ \\
& & 0.030 & 0.060 & 0.070 & 0.250 & 0.360 & 0.430 \\
\hline 2 & $\mathrm{Mn}$ & $0.060 /$ & $0.080 /$ & $0.230 /$ & $0.720 /$ & $0.820 /$ & $0.860 /$ \\
& & 0.030 & 0.030 & 0.060 & 0.190 & 0.370 & 0.920 \\
\hline 3 & $\mathrm{Si}$ & $0.060 /$ & $0.050 /$ & $0.260 /$ & $0.610 /$ & $0.750 /$ & $0.710 /$ \\
& & 0.030 & 0.040 & 0.070 & 0.150 & 0.390 & 0.590 \\
\hline 4 & $\mathrm{~S}$ & $0.013 /$ & $0.025 /$ & $0.017 /$ & $0.016 /$ & 0.028 & $0.016 /$ \\
& & 0.060 & 0.027 & 0.035 & 0.028 & $/ 0.023$ & 0.028 \\
\hline 5 & $\mathrm{P}$ & $0.015 /$ & $0.020 /$ & $0.021 /$ & $0.023 /$ & $0.022 /$ & $0.022 /$ \\
& & 0.030 & 0.018 & 0.012 & 0.018 & 0.018 & 0.019 \\
\hline 6 & $\mathrm{Cr}$ & $0.030 /$ & $0.040 /$ & $0.050 /$ & $0.060 /$ & $0.070 /$ & $0.070 /$ \\
& & 0.020 & 0.020 & 0.030 & 0.040 & 0.060 & 0.070 \\
\hline 7 & $\mathrm{Ni}$ & $0.120 /$ & $0.120 /$ & $0.100 /$ & $0.110 /$ & $0.100 /$ & $0.110 /$ \\
& & 0.120 & 0.120 & 0.080 & 0.120 & 0.110 & 0.110 \\
\hline 8 & $\mathrm{Cu}$ & $0.200 /$ & $0.170 /$ & $0.140 /$ & $0.140 /$ & $0.150 /$ & $0.190 /$ \\
& & 1.430 & 1.290 & 1.070 & 1.270 & 1.310 & 1.360 \\
\hline 9 & $\mathrm{Al}$ & $0.012 /$ & $0.011 /$ & $0.078 /$ & $1.480 /$ & $3.090 /$ & $4.130 /$ \\
& & 0.012 & 0.016 & 0.019 & 0.310 & 0.930 & 2.900 \\
\hline 10 & $\mathrm{Fe}$ & $99.240 /$ & $98.144 /$ & $97.114 /$ & $94.991 /$ & $93.390 /$ & $92.422 /$ \\
& & 98.238 & 98.379 & 98.554 & 97.624 & 96.429 & 93.573 \\
\hline
\end{tabular}

*Numerator is reductant 1, denominator is reductant 2

According to the obtained data, chemical composition of experimental metals corresponds to iron-carbon alloys and in some cases corresponds to 
the range established by the regulatory documentation and can be identified as graded steel with chemical composition determined by the corresponding GOST. For example, when using thermite with reductant 1 in the amount of $20 \%$, the resulting experimental alloy corresponds to the chemical composition of steel A4 as per GOST 31334-2007. When introducing it in the amounts of 22 and $23 \%$, the alloys correspond to electric steel 3311 per GOST 21427.1-83. Structures of the samples obtained from mixtures with reductant content 20 and $22 \%$ contain Widmannstetter ferrite and cementite formed inside austenite grains and are shown in Figure 2.

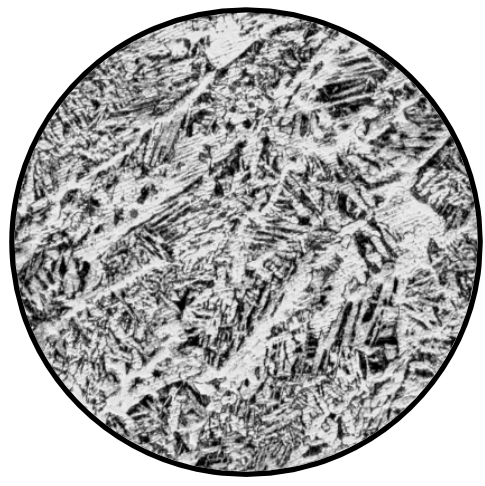

a.

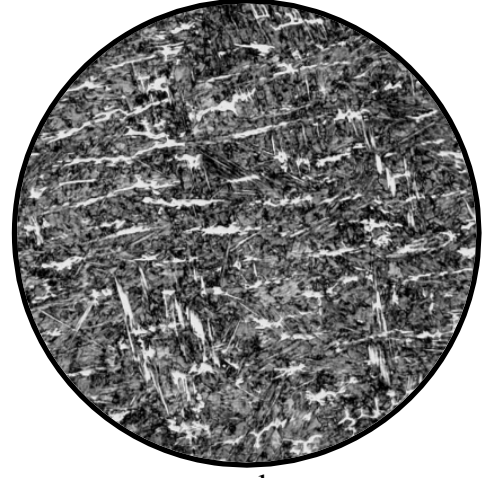

b.

Fig. 2. Structures of Samples Obtained Using Aluminothermy: a is $20 \%$ of Reductant 1 ; $b$ is $22 \%$ of Reductant 1

Physicomechanical properties of the resulting blanks are mostly determined by carbon content in the alloys and the conditions of casting crystallization. The higher carbon content is, the higher its strength and hardness are. Ultimate strength and elongation of the considered alloys reaches $450 \mathrm{MPa}$ at $22.15 \%$ and $527 \mathrm{MPa}$ at $1.18 \%$, correspondingly. The hardness of the specified experimental alloys is 130 and $414 \mathrm{HBW}$. Correction of physicomechanical properties and structures of the obtained experimental alloys is possible by using thermal treatment. In a number of cases, following the annealing of aluminothermic alloys, there is some strength increase due to the rectification of inner stresses developed in certain crystallization conditions.

Various additives are used to increase thermite metal output and correct its properties. Figure 3 (a) shows functional connection of metal phase output and quantity of the introduced ferrous metal swarf which is mechanical engineering facility waste. It has been established that introducing steel swarf when using compounds with reductant to scale ratio 22/78 leads to metal output increase up to $5 \%$. Introducing scheelite concentrate into thermites (Figure 3, b) under otherwise equal conditions, reduces metal phase output to $20 \%$. However, it facilitates enrichment of experimental alloys with tungsten and obtaining special steel grades. Tables 2 and 3 show chemical composition of alloys obtained using aluminothermy with introduction of corresponding fillers. 
Table 2. Chemical Composition of Experimental Alloys with Ferrous Metal Swarf Introduction

\begin{tabular}{|c|c|c|c|c|c|c|c|c|}
\hline \multirow{2}{*}{ No. } & \multirow{2}{*}{ Element } & \multicolumn{9}{|c|}{ Reductant Content, \% } & \multicolumn{7}{c|}{ T.3 } \\
\cline { 3 - 9 } & & 0 & 0.1 & 1.6 & 2.9 & 4.3 & 5.6 & 6.5 \\
\hline 1. & $\mathrm{C}$ & 1.95 & 1.93 & 1.87 & 1.83 & 1.83 & 1.32 & 0.38 \\
\hline 2. & $\mathrm{Mn}$ & 0.24 & 0.25 & 0.29 & 0.29 & 0.28 & 0.28 & 0.32 \\
\hline 3. & $\mathrm{Si}$ & 0.25 & 0.25 & 0.28 & 0.26 & 0.24 & 0.24 & 0.24 \\
\hline 4. & $\mathrm{~S}$ & 0.013 & 0.015 & 0.017 & 0.016 & 0.016 & 0.017 & 0.038 \\
\hline 5. & $\mathrm{P}$ & 0.017 & 0.017 & 0.027 & 0.026 & 0.027 & 0.027 & 0.02 \\
\hline 6. & $\mathrm{Cr}$ & 0.05 & 0.05 & 0.05 & 0.05 & 0.05 & 0.05 & 0.05 \\
\hline 7. & $\mathrm{Ni}$ & 0.1 & 0.1 & 0.1 & 0.1 & 0.11 & 0.11 & 0.11 \\
\hline 8. & $\mathrm{Cu}$ & 0.15 & 0.15 & 0.16 & 0.16 & 0.16 & 0.16 & 0.17 \\
\hline 9. & $\mathrm{Al}$ & 0.085 & 0.085 & 0.26 & 0.22 & 0.32 & 0.44 & 1.02 \\
\hline 10. & $\mathrm{Fe}$ & 97.145 & 97.153 & 96.946 & 97.048 & 96.967 & 97.356 & 97.652 \\
\hline
\end{tabular}

Table 3. Chemical Composition of Experimental Alloys with Scheelite Concentrate Introduction

\begin{tabular}{|c|c|c|c|c|c|c|}
\hline \multirow{2}{*}{ No. } & \multirow{2}{*}{ Element } & \multicolumn{5}{|c|}{ Reductant Content, \% } \\
\cline { 3 - 7 } & & 0 & 5 & 10 & 15 & 20 \\
\hline 1. & $\mathrm{C}$ & 0.240 & 0.440 & 0.280 & 0.320 & 0.300 \\
\hline 2. & $\mathrm{Mn}$ & 0.270 & 0.250 & 0.140 & 0.090 & 0.050 \\
\hline 3. & $\mathrm{Si}$ & 0.300 & 0.280 & 0.140 & 0.100 & 0.050 \\
\hline 4. & $\mathrm{~S}$ & 0.088 & 0.125 & 0.150 & 0.169 & 0.217 \\
\hline 5. & $\mathrm{P}$ & 0.014 & 0.116 & 0.180 & 0.287 & 0.347 \\
\hline 6. & $\mathrm{Cr}$ & 0.030 & 0.030 & 0.030 & 0.030 & 0.030 \\
\hline 7. & $\mathrm{Ni}$ & 0.090 & 0.070 & 0.070 & 0.050 & 0.050 \\
\hline 8. & $\mathrm{Cu}$ & 0.160 & 0.170 & 0.180 & 0.110 & 0.110 \\
\hline 9. & $\mathrm{Al}$ & 0.440 & 0.820 & 0.350 & 0.230 & 0.010 \\
\hline 10. & $\mathrm{~W}$ & 0.084 & 4.930 & 8.330 & 15.793 & 20.759 \\
\hline 11. & $\mathrm{Fe}$ & 98.284 & 92.769 & 90.150 & 82.821 & 78.077 \\
\hline
\end{tabular}




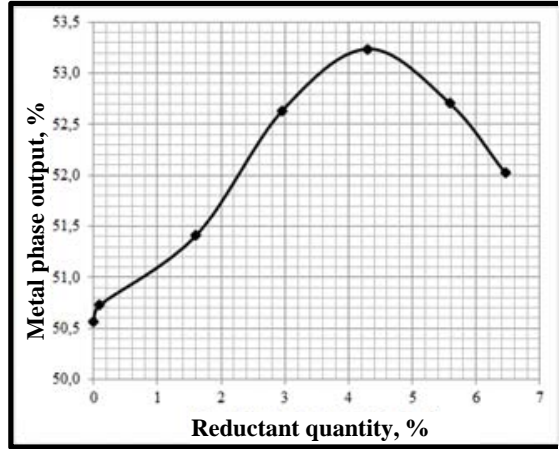

a.

Fig. 3. Metal Phase Output when Using Fillers for Thermites: a is Steel Swarf; $b$ is Scheelite Concentrate, $5 \%$.

Currently, the alloys obtained using aluminothermy are used in production of castings and parts for various purposes. Figure 4 shows castings for a screw pile cone and steel grinding balls for ball mills which successfully passed industrial testing.

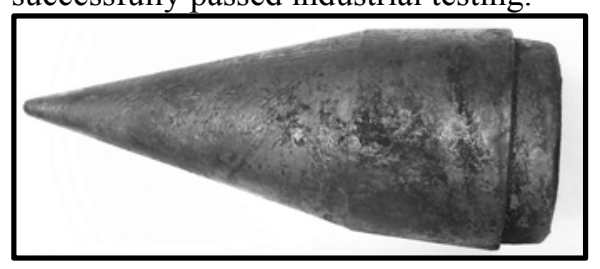

a.

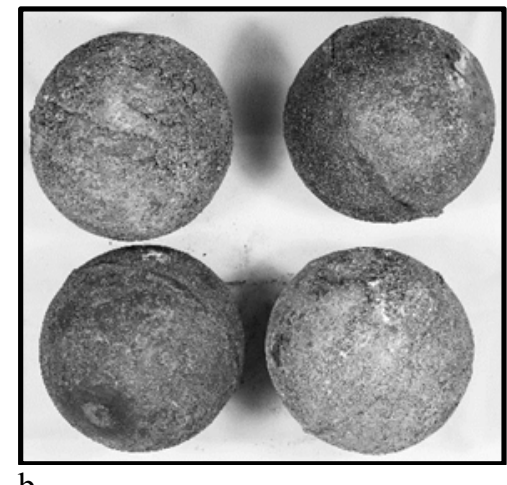

b.

Fig. 4. Castings Made of Aluminothermic Alloys: $\mathbf{a}$ is Screw Pile Cone; $\mathbf{b}$ is Steel Grinding Balls (dia. $120 \mathrm{~mm}$ ).

Blanks made using aluminothermy and having non-rectifiable defects like gas unsoundness, misruns, runouts, etc. are remelted as melting stock in traditional melting units. The studies on remelting experimental alloys in the induction melting unit ИСТ-0.06 with lining made of fused magnesite powder showed that it is possible to obtain non-defective castings with uniform impurity element distribution and high surface quality [12].

\section{Conclusion}

As is seen above, aluminothermy allows effective processing of mechanical engineering and metallurgy facilities waste by returning secondary raw material to the production cycle and reducing the use of the new one, which supplies blank production for mechanical engineering with the required cheap materials. It has been determined that it is possible to obtain experimental alloys with varying chemical composition and properties, including those complying with regulatory documentation, by adding various fillers to thermites which ensure high metal phase output and required reaction product temperatures. The conducted studies established that it is possible to use oxides when making alloys to enrich liquid metal with the required elements, 
e.g. tungsten, and control its properties. Low quality castings obtained from metal waste and having certain non-rectifiable casting defects are also a functional product which may be used as melting stock to prepare liquid metal using traditional melting units and make high-quality castings. High national economic significance of the presented technologies is defined both by the possibility of reducing mining load by involving hard to recycle manmade mineral formations into production as well as by obtaining wearresistant structural elements used in mining. Therefore, aluminothermy is a promising way of integrated available raw material processing, including metal waste of industrial facilities, with simultaneous manufacturing of high quality metal products with high operational characteristics used in production of critical parts and blanks.

\section{References}

1. M.Sh. Barkan, M.A. Pashkevich, N.V. Gurova, EKiP 11, 19-21 (2007). (in Russian)

2. V.S. Dadykin, Bulletin of SSEU, 11(157), 35-39 (2017). (in Russian)

3. Z.M. Bobrova, O. Yu. Ilyina, A.V. Khokhryakov, E.M. Zeitlin, Izvestiya UGGU, 4(40), 16-26 (2015). (in Russian)

4. O.N. Komarov, S.G. Zhilin, V.V. Predein, A.V. Popov, Metallurgy, 8, 90101 (2020). (in Russian)

5. V.A. Novokhatskiy, Low-waste technology for the production of steel castings with exothermic profits (Mechanical engineering, 1986). (in Russian)

6. A. G. Merzhanov, Russian Chemical Reviews, 45(5), 827 (1976)

7. David G. Morris, Maria A. Munoz-Morris, Jesus Chao, Intermetallics, 12, 821-826 (2004)

8. Y. Zhanga, B.A. Pint, G.W. Garner, K.M. Cooley, J.A Haynes, Surf. Coat. Technol., 188-189, 35- 40 (2004)

9. V.L. Sirovatka, V.E. Oliker, M.S. Yakovleva, Materials Science, 3, 46-52 (2013). (in Russian)

10. A.G. Tyurin, A.I. Smirnov, D.S. Terentyev, E.M. Parygina, Metal processing, 3 (48), 32-36 (2010). (in Russian)

11. V.V. Gostishchev, I.A. Astapov, A.V. Medneva, R. Hosen, S.N. Khimukhin, Izvestiya VUZov. Non-ferrous metallurgy, 6, 63-69 (2015). (in Russian)

12. A.V. Popov, O.N. Komarov, V.V. Predein, S.G. Zhilin, AIP Conf. Proc. 2053, 040076-1-040076-6 (2018) 